\title{
Optimal Combined Purchasing Strategies for a Risk-Averse Manufacturer Under Price Uncertainty
}

\author{
Qiao Wu ${ }^{1}$, Andy Chen ${ }^{2}$ \\ ${ }^{1}$ School of Modern Logistics, Zhejiang Wanli University (China) \\ ${ }^{2}$ School of Management, Zhejiang University (China) \\ 10920005@,zju.edu.cn,arnon41@,botmail.com
}

Received: October 2014

Accepted: July 2015

\section{Abstract:}

Purpose: Our paper is to analyze optimal purchasing strategies when a manufacturer can buy raw materials from a long-term contract supplier and a spot market under spot price uncertainty.

Design/methodology/approach: The procurement model is solved by using dynamic programming. First, we maximize the DM's utility of the second period, obtaining the optimal contract quantity and spot quantity for the second period. Then, maximize the DM's utility of both periods, obtaining the optimal purchasing strategy for the first period. We use a numerical method to compare the performance level of a pure spot sourcing strategy with that of a mixed strategy.

Findings: Our results show that optimal purchasing strategies vary with the trend of contract prices. If the contract price falls, the total quantity purchased in period 1 will decrease in the degree of risk aversion. If the contract price increases, the total quantity purchased in period 1 will increase in the degree of risk aversion. In period 2, the relationship between the optimal contract quantity and the degree of risk aversion depends on whether the expected spot price or the contract price is larger. Finally, we compare the performance levels between a combined strategy and a spot sourcing strategy. It shows that a combined strategy is optimal for a riskaverse buyer. 
Originality/value: It's challenging to deal with a two-period procurement problem with risk consideration. We have obtained results of a two-period procurement problem with two sourcing options, namely contract procurement and spot purchases. Our model incorporates the buyer's risk aversion factor and the change of contract prices, which are not addressed in early studies.

Keywords: price risk, risk aversion, spot market, combined strategy

\section{Introduction}

Prices of raw materials fluctuate a lot in the era of globalization. The fluctuation brings a great risk to the procurement process of a company. Many manufacturers fall into trouble as they may suffer huge losses. For example, a can making company lost 20 million in 2010, because this company stored 10,000 tons of steel plate and the price fell 2000 yuan one ton.

The procurement cost of raw materials accounts for $60-80 \%$ of the revenue in manufacturing. The fluctuation of raw-material prices greatly influences the stability of profits. Therefore, many companies are adopting proper strategies to control procurement cost. For example, Hewlett-Packard (HP) has implemented an active procurement risk management (PRM) program. Different and flexible purchasing methods, such as a long-term contract, a spot market and an option contract, are used to meet demands based on a project's risk evaluation in this program (Nagali, Hwang, Sanghera, Gaskins, Pridgen, Thurston et al., 2008).

Traditionally, a manufacturer can buy raw materials from a supplier via a long-term contract. A purchasing price and a quantity are specified in a long-term contract. Recently, the spot market plays an important role in resource allocation, as many raw materials are traded in the spot market. Many online exchange markets emerge with the rapid development of information technology, such as ChemConnect for chemical products, E-Steel for steel and Converge for semiconductors, which significantly reduce the transaction cost through a spot market. Therefore, more and more spot purchasing is used for raw materials. It is recognized that a long-term contract and a spot market can be combined to manage the procurement risk in a volatile environment.

In this paper a manufacturer need to purchase raw materials to meet the demand of two periods. Our aim is to analyze the optimal purchasing strategies when the manufacturer can buy raw materials from a long-term contract supplier and a spot market. The remainder of the paper is organized as follows. In section 2, we review the relevant research. In section 3, we describe our purchasing model in detail, and derive the optimal purchasing strategies. Section 4 compares the performance level of a combined strategy with that of a spot sourcing strategy. We give a summary of important results in Section 5 . 


\section{Literature Review}

Our work is to analyze optimal purchasing strategies when a manufacturer can buy raw materials from a long-term contract supplier and a spot market. A lot of literature in operations management has addressed different aspects of procurement. The most relevant literature is the research on dual sourcing and sourcing with a spot market.

The effect of dual sourcing on optimal inventory policies is studied by some scholars. Donohue (2000) studies efficient supply contracts for fashion goods with two production mode. The buyer may order goods at a lower price at the beginning of a sales period; or make additional order at a higher price in the sales period. Chung and Flynn (2001), and Warburton and Stratton (2005) discuss a newsboy problem with two ordering opportunities. The later ordering point can be regarded as a spot purchase.

Optimal purchasing strategies are then studied in the presence of a spot market. Serel, Dada, and Moskowitz (2001) examine sourcing decisions of a firm in the presence of a spot market. Their study shows that inclusion of a spot sourcing reduces the capacity commitments from a long-term supplier. Moreover, Serel (2007) study capacity reservation under supply uncertainty. Lee and Whang (2002) consider the impact of a secondary market, where buyers can trade their excess inventory. They show that the introduction of a secondary market will improve allocative efficiency but the welfare of the supplier may not increase. In these works, the spot price is deterministic.

Spot price uncertainty is considered for an inventory policy by Cohen and Agrawal (1999). They evaluate the tradeoff between long-term contracts and short-term contracts. Peleg, Lee and Hausman (2002) compare procurement strategies among three arrangements, a long-term contract, online search and a combination strategy. Kleindorfer et al. (Kleindorfer \& Wu, 2003, 2005; Wu, Kleindorfer, \& Zhang, 2002) have studied procurement problems via integrating long-term and short-term contracts. Their research mainly focuses on capital-intensive industries, and has contributed a lot to this area.

A large proportion of the literature has studied purchasing strategies in a one-period setting (Arnold \& Minner, 2011; Fu, Lee, \& Teo, 2010; Seifert, Thonemann, \& Hausman, 2004). Araman, Kleinknecht and Akella (2001) model a buyer who can procure either through a contract, a spot market, or a combination of both. A spot market is used when preserved capacity can not fulfill demand. It is demonstrated that the spot market is beneficial from the perspective of the buyer. Seifert et al. (2004) develop a model for a buyer's optimal strategy; their results show that significant profit improvement can be achieved by adopting a combined strategy. Arnold and Minner (2011) find the best mix of advance procurement, spot market procurement, and financial options to satisfy demand. A multi-period setting is not considered in their works, which is one main concern in our paper. 
Recently, some authors are exploring the purchasing problem in a multi-period setting. Ganeshan, Boone and Aggarwal (2009) show managers can integrate risk management tools to mitigate risk over multiple time periods. Inderfurth and Kelle (2011) show that the combined strategy is superior over single sourcing strategy if there is large spot price variability. But risk aversion is not addressed in their papers.

Kouvelis, Li and Ding (2013) study a procurement problem for a risk-averse buyer who procures a single commodity from a supplier via a long-term contract and via short-term purchases from a spot market. Multi-period optimal inventory and financial hedging policies are obtained. Our research model is similar to their model, as we study a two-period procurement problem for a risk-averse manufacturer. The main difference is that the contract price changes in our model, and it remains constant in theirs. We investigate how the trend of the contract price influences optimal purchasing strategies. In addition, we compare a combined strategy and a single sourcing strategy based on their profits and utilities. And we also analyze how the profits and utilities depend on the degree of risk aversion.

\section{Optimal Procurement Strategy Combining Contract Market and Spot Market}

Considering a raw-material purchase for a manufacturer, this company will need two batches of raw materials in 3 months and 6 months later (marked as period 1 and period 2 below, Figure 1), one batch for each period. Raw materials are used to produce end products for customers, and the amount of materials needed is proportional to the output of end products. The manufacturer should buy materials to meet the demand for production, and try to reduce the purchasing cost.

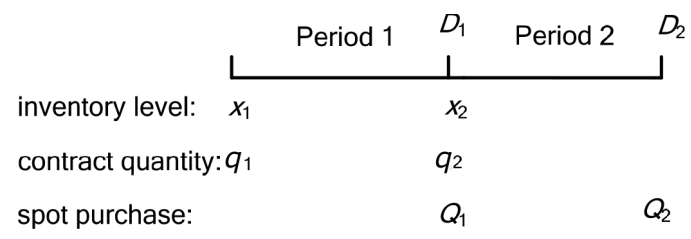

Figure 1. A two-period procurement model

The manufacturer can buy materials from a supplier via a long-term contract or from a spot market. At the beginning of period 1 , the inventory level is $x_{1}$. The spot price $p_{1}$ is unknown. A decision maker (DM) decides the order quantity from a supplier for period 1 . At the end of period $1, p_{1}$ is realized. The quantity ordered $q_{1}$ is received and demand $D_{1}$ occurs. And the DM decides quantity $Q_{1}$ to purchase from a spot market. Insufficient materials should be purchased from the spot market in shortage, or excess materials are left for use at period 2. 
At the beginning of period 2, the inventory level is $x_{2}$. The spot price $p_{2}$ is unknown. Similarly, the DM decides the order quantity for period 2. At the end of period 2, $p_{2}$ is realized. Insufficient materials are purchased from a spot market, or excess materials are sold in the spot market. The notations used in this paper are given in Table 1.

\begin{tabular}{|l|l|}
\hline Notations & Meaning \\
\hline$x_{1}, x_{2}$ & Inventory level at the beginning of each period \\
\hline$q_{1}, q_{2}$ & Quantity ordered at the beginning of each period \\
\hline$Q_{1}, Q_{2}$ & Quantity purchased from a spot market \\
\hline$D_{1}, D_{2}$ & Materials demand at the end of each period \\
\hline$c_{1}, c_{2}$ & Contract price of raw materials \\
\hline$p_{1}, p_{2}$ & Spot price of raw materials \\
\hline$\mu_{1}, \mu_{2}$ & Expected spot price of raw materials \\
\hline$\sigma_{1}, \sigma_{2}$ & Standard deviation of spot price \\
\hline$\pi_{1}, \pi_{2}$ & Manufacturer's profit \\
\hline$k$ & Decision maker's risk aversion factor $(k>0)$ \\
\hline$U_{1}, U_{2}$ & Decision maker's utility function \\
\hline$r$ & Sales price of the product \\
\hline
\end{tabular}

Table 1. Notations

Demand for production in each period must be satisfied, that is, shortage of materials is not allowed. $x_{1}$ equals zero, and $x_{2}$ is not less than zero. The spot price of raw materials is exogenous, determined by the raw materials market. The sales price is assumed to be higher than the corresponding cost of materials consumed, that is $r>p_{i}, r>c_{i}, I=1,2$.

This procurement model can be solved by using dynamic programming. First, we maximize the DM's utility of the second period, obtaining the optimal contract quantity and spot quantity for the second period. Then, maximize the DM's utility of both periods, obtaining the optimal purchasing strategy for the first period.

The manufacturer's profit is the revenue of products minus the cost of raw materials, so the profit in period 2 is

$$
\pi_{2}\left(x_{2}\right)=r D_{2}-c_{2} q_{2}-p_{2} Q_{2}
$$

where the first item in RHS is the revenue of products, the second item is the ordering cost via a long-term contract, and the third item is the purchasing cost via a spot market. 
Correspondingly, the DM's mean-variance utility function (Gan, Sethi \& Yan, 2004) of period 2 is

$$
U_{2}\left(x_{2}\right)=E\left(\pi_{2}\right)-k \operatorname{Var}\left(\pi_{2}\right),
$$

where $k$ is bigger than 0 . The larger $k$ is, the more conservative the DM is.

At the beginning of period 2, the DM determines an ordering policy $\left(q_{2}, Q_{2}\right)$ so as to maximize his utility. That is

$$
\begin{aligned}
& V_{2}\left(x_{2}\right)=\max _{q_{2}, Q_{2}} U_{2}\left(x_{2}\right)=\max _{q_{2}, Q_{2}}\left\{E\left(\pi_{2}\right)-k \operatorname{Var}\left(\pi_{2}\right)\right\} . \\
& \text { s.t. } x_{2}+q_{2}+Q_{2}=D_{2}, \\
& \qquad x_{2}, q_{2} \geq 0 .
\end{aligned}
$$

The first constraint implies that demand for production in period 2 is satisfied.

$x_{2}$ equals the total materials purchased minus its consumption in period 1 , that is, $x_{2}=q_{1}+Q_{1}-D_{1}$.

Similarly, the manufacturer's profit is $\pi_{1}\left(x_{1}\right)=r D_{1}-c_{1} q_{1}-p_{1} Q_{1}$ in period 1 , and the corresponding utility is $U_{1}\left(x_{1}\right)=E\left(\pi_{1}\right)-k \operatorname{Var}\left(\pi_{1}\right)$.

The DM determines an ordering policy $\left(q_{1}, Q_{1}\right)$ at the start of period 1 , maximizing the sum of utilities for both periods.

$$
\begin{aligned}
& V_{1}\left(x_{1}\right)=\max _{q_{1}, Q_{1}}\left\{U_{1}+V_{2}\left(x_{2}\right)\right\}=\max _{q_{1}, Q_{1}}\left\{E\left(\pi_{1}\right)-k \operatorname{Var}\left(\pi_{1}\right)+V_{2}\left(x_{2}\right)\right\}, \\
& \text { s.t. } x_{1}+q_{1}+Q_{1} \geq D_{1}, \\
& \quad x_{1}=0 \\
& \quad q_{1}, Q_{1} \geq 0 .
\end{aligned}
$$

\subsection{Optimal Purchasing Strategy in Period 2}

Proposition 1. The optimal contract quantity and spot quantity purchased are $q_{2}^{*}=D_{2}-x_{2}+\frac{\mu_{2}-c_{2}}{2 k \sigma_{2}^{2}}, Q_{2}^{*}=\frac{c_{2}-\mu_{2}}{2 k \sigma_{2}^{2}}$ in period 2, if $D_{2}-x_{2}+\frac{\mu_{2}-c_{2}}{2 k \sigma_{2}^{2}} \geq 0$

The optimal purchasing strategy is $q_{2}^{*}=0, Q_{2}^{*}=D_{2}-x_{2}$ in period 2, if $D_{2}-x_{2}+\frac{\mu_{2}-c_{2}}{2 k \sigma_{2}^{2}}<0$.

Proof:

$D_{1}=x_{2}+Q_{2} D_{1}$, so $E\left(\pi_{2}\right)=E\left(r D_{2}-c_{2} q_{2}-p_{2} Q_{2}\right)=\left(r-\mu_{2}\right) D_{2}+\left(\mu_{2}-c_{2}\right) q_{2}+\mu_{2} x_{2}$ and $\operatorname{Var}\left(\pi_{2}\right)=\left(Q_{2}\right)^{2} \operatorname{Var}\left(p_{2}\right)=\left(D_{2}-x_{2}-q_{2}\right)^{2} \sigma_{2}^{2}$. 
Substitute $E\left(\pi_{2}\right)$ and $\operatorname{Var}\left(\pi_{2}\right)$ into Equation (1), we can get

$$
\begin{aligned}
& V_{2}\left(x_{2}\right)=\max _{q_{2}} U_{2}\left(x_{2}\right) \\
& =\max _{q_{2}}\left\{-k \sigma_{2}^{2} q_{2}^{2}+2 k \sigma_{2}^{2}\left(D_{2}-x_{2}\right) q_{2}+\left(\mu_{2}-c_{2}\right) q_{2}+\left(r-\mu_{2}\right) D_{2}+\mu_{2} x_{2}-k \sigma_{2}^{2}\left(D-x_{2}\right)^{2}\right\} .
\end{aligned}
$$

$-k \sigma_{2}^{2}<0, U_{2}$ is concave, so the maximum value exists. We can get the following results,

(i) When $D_{2}-x_{2}+\frac{\mu_{2}-c_{2}}{2 k \sigma_{2}^{2}} \geq 0, q_{2}^{*}=D_{2}-x_{2}+\frac{\mu_{2}-c_{2}}{2 k \sigma_{2}^{2}}$. Therefore, $Q_{2}^{*}=D_{2}-x_{2}-q_{2}^{*}=\frac{c_{2}-\mu_{2}}{2 k \sigma_{2}^{2}}$;

(ii) When $D_{2}-x_{2}+\frac{\mu_{2}-c_{2}}{2 k \sigma_{2}^{2}}<0, q_{2}^{*}=0$. Therefore, $Q_{2}^{*}=D_{2}-x_{\text {, }}$.

Proposition 1 can be concluded from (i) and (ii). The ordering quantity via a long-term contract is greater than 0 at the beginning of period 2 in case (i). And the ordering quantity is 0 in case (ii).

Corollary 1. When the optimal contract quantity $q_{2}^{*}$ is larger than $0, q_{2}^{*}$ decreases in $k$ if $\mu_{2}>c_{2} ; q_{2}^{*}$ does not change in $k$ if $\mu_{2}=c_{2} ; q_{2}^{*}$ increases in $k$ if $\mu_{2}<c_{2}$.

Proof: From Proposition 1, the relationship between the optimal contract quantity $q_{2}^{*}$ and the degree of risk aversion $k$ depends on the sign of $\left(\mu_{2}-c_{2}\right)$. Therefore, corollary 1 can be derived.

\subsection{Optimal Purchasing Strategy in Period 1}

The optimal purchasing strategy of period 1 can be derived, after having obtained the optimal purchasing strategy of period 2 .

The expected value and variance of $\Pi_{1}$ are

$E\left(\pi_{1}\right)=E\left(r D_{1}-c_{1} q_{1}-p_{1} Q_{1}\right)=r D_{1}-c_{1} q_{1}-\mu_{1} Q_{1}$,

$\operatorname{Var}\left(\pi_{1}\right)=\left(Q_{1}\right)^{2} \operatorname{Var}\left(p_{1}\right)=. Q_{1}^{2} \sigma_{1}^{2}$

Substitute $E\left(\pi_{1}\right)$ and $\operatorname{Var}\left(\pi_{1}\right)$ into Equation (2), we can get

$$
V_{1}\left(x_{1}\right)=\max _{q_{1}, Q_{1}}\left\{r D_{1}-c_{1} q_{1}-\mu_{1} Q_{1}-k Q_{1}^{2} \sigma_{1}^{2}+V_{2}\right\}
$$


Proposition 2. When the contract price of raw materials falls $\left(c_{1}>c_{2}\right)$, the total materials purchased in period 1 are as follows.

$q_{1}^{*}+Q_{1}^{*}=D_{1}$, if $\mu_{1} \geq c_{2}-2 k \sigma_{1}^{2} D_{1} ;$

$q_{1}^{*}+Q_{1}^{*}=\frac{c_{2}-\mu_{1}}{2 k \sigma_{1}^{2}}$, if $\mu_{1}<c_{2}-2 k \sigma_{1}^{2} D_{1}$.

Proof:

When $c_{1}>c_{2}$, substitute optimal quantities $\left(q_{2}^{*}, Q_{2}^{*}\right)$ in proposition 1 into Equation (4), and we can get

$$
\begin{aligned}
V_{1}\left(x_{1}\right)= & \max _{q_{1}, Q_{1}}\left\{-\left(c_{1}-c_{2}\right) q_{1}-k \sigma_{1}^{2} Q_{1}^{2}-\left(\mu_{1}-c_{2}\right) Q_{1}+a\right\}, \\
\text { s.t. } & q_{1}+Q_{1} \geq D_{1}, \\
& q_{1}+Q_{1} \leq D_{1}+D_{2}, \\
& q_{1}, Q_{1} \geq 0 .
\end{aligned}
$$

Where $a=\left(r-c_{2}\right)\left(D_{1}+D_{2}\right)+\frac{\left(\mu_{2}-c_{2}\right)^{2}}{4 k \sigma_{2}^{2}}$.

Use $z$ to denote the total utility, $z\left(q_{1}, Q_{1}\right)=-\left(c_{1}-c_{2}\right) q_{1}-k \sigma_{1}^{2} Q_{1}^{2}-\left(\mu_{1}-c_{2}\right) Q_{1}+a$. The Hesse matrix of $z$ is $H(z)=\left[\begin{array}{cc}-2 k \sigma_{1}^{2} & 0 \\ 0 & 0\end{array}\right]$, which is negative semi-define, so $z$ is concave, and the maximum value exists.

The Lagrangian function of $z$ is

$$
L\left(q_{1}, Q_{1}\right)=z\left(q_{1}, Q_{1}\right)+\lambda_{1} q_{1}+\lambda_{2} Q_{1}
$$

From Equation (6), we can obtain the optimal purchasing quantities as follows. Denote $\frac{c_{1}-\mu_{1}}{2 k \sigma_{1}^{2}}$ by $Q_{1}^{t}$.

(i) $\mu_{1} \geq c_{2}-2 k \sigma_{1}^{2} D_{1}$

If $\mu_{1} \leq c_{1} \leq \mu_{1}+2 k \sigma_{1}^{2} D_{1}$, the optimal ordering policy is $\left(q_{1}^{*}, Q_{1}^{*}\right)=\left(D_{1}-Q_{1}^{t}, Q_{1}^{t}\right)$;

if $c_{1}<\mu_{1}$, the optimal ordering policy is $\left(q_{1}^{*}, Q_{1}^{*}\right)=\left(D_{1}, 0\right)$;

if $c_{1}>\mu_{1}+2 k \sigma_{1}^{2} D_{1}$, the optimal ordering policy is $\left(q_{1}^{*}, Q_{1}^{*}\right)=\left(0, D_{1}\right)$.

(ii) $\mu_{1}<c_{2}-2 k \sigma_{1}^{2} D_{1}$

The optimal ordering policy is $\left(q_{1}^{*}, Q_{1}^{*}\right)=\left(0, \frac{c_{2}-\mu_{1}}{2 k \sigma_{1}^{2}}\right)$. 
Proposition 2 can be concluded based on case (i) and case (ii).

The quantity ordered via a long-term contract and the quantity purchased via a spot market in period 1 are also derived in both cases.

Corollary 2. When the contract price of raw materials falls $\left(c_{1}>c_{2}\right)$, the total materials purchased in period 1 decrease in $k$.

Proof:

From case (i) of Proposition 2, if $\mu_{1} \geq c_{2}-2 k \sigma_{1}^{2} D_{1}, q_{1}^{*}+Q_{1}^{*}=D_{1}$. As $k$ increases, $\left(c_{2}-2 k \sigma_{1}^{2} D_{1}\right)$ becomes smaller and $\mu_{1}$ is more likely larger than $\left(c_{2}-2 k \sigma_{1}^{2} D_{1}\right)$. Therefore, $\left(q_{1}^{*}+Q_{1}^{*}\right)$ is more likely to be $D_{1}$, which is less than the total quantity in case (ii).

From case (ii) of Proposition $2, q_{1}^{*}+Q_{1}^{*}=\frac{c_{2}-\mu_{1}}{2 k \sigma_{1}^{2}} . \mu_{1}<c_{2}-2 k \sigma_{1}^{2} D_{1}<c_{2}$, so $\left(q_{1}^{*}+Q_{1}^{*}\right)$ decreases in $k$. Based on both cases, Corollary 2 is true.

Proposition 3. When the contract price of raw materials increases $\left(c_{1}<c_{2}\right)$, the optimal purchasing quantities in period 1 are as follows.

If $\mu_{1}>c_{1}$ or if $\mu_{1} \leq c_{1}$ and $\left(D_{1}+D_{2}\right)+\frac{\mu_{2}-c_{1}}{2 k \sigma_{2}^{2}}-\frac{c_{1}-\mu_{1}}{2 k \sigma_{1}^{2}} \geq 0$, the total quantity purchased in period 1 is $\min \left\{\left(D_{1}+D_{2}\right)+\frac{\mu_{2}-c_{1}}{2 k \sigma_{2}^{2}}, D_{1}+D_{2}\right\}$

Otherwise, the total quantity purchased in period 1 is $\min \left\{\left(D_{1}+D_{2}\right) \frac{\sigma_{2}^{2}}{\sigma_{1}^{2}+\sigma_{2}^{2}}+\frac{\mu_{2}-\mu_{1}}{2 k\left(\sigma_{1}^{2}+\sigma_{2}^{2}\right)}, D_{1}+D_{2}\right\}$.

Proof:

When $c_{1}<c_{2}$, substitute the optimal quantities $\left(q_{2}^{*}, Q_{2}^{*}\right)$ in proposition 1 into Equation (4), and we can get

$$
\begin{aligned}
V_{1}\left(x_{1}\right)=\max _{q_{1}, Q_{1}}\left\{U_{1}+V_{2}\right\} & \\
=\max _{q_{1}, Q_{1}} & \left\{-k \sigma_{2}^{2} q_{1}^{2}+\left(-c_{1}+\mu_{2}+2 k \sigma_{2}^{2}\left(D_{1}+D_{2}\right)\right) q_{1}+\right. \\
& \left(-k \sigma_{1}^{2}-k \sigma_{2}^{2}\right) Q_{1}^{2}+\left(-\mu_{1}+\mu_{2}+2 k \sigma_{2}^{2}\left(D_{1}+D_{2}\right)\right) Q_{1}- \\
& \left.2 k \sigma_{2}^{2} q_{1} Q_{1}+\left(r-\mu_{2}\right)\left(D_{1}+D_{2}\right)-k \sigma_{2}^{2}\left(D_{1}+D_{2}\right)^{2}\right\},
\end{aligned}
$$


The Lagrangian function of Equation (7)'s objective function is

$$
L\left(q_{1}, Q_{1}\right)=U_{1}+V_{2}+\lambda_{1} q_{1}+\lambda_{2} Q_{1}
$$

and its Kuhn-Tucker conditions are

$$
\begin{gathered}
-2 k \sigma_{2}^{2}\left(q_{1}+Q_{1}\right)+2 k \sigma_{2}^{2}\left(D_{1}+D_{2}\right)-c_{1}+\mu_{2}+\lambda_{1}=0, \\
-2 k\left(\sigma_{1}^{2}+\sigma_{2}^{2}\right) Q_{1}-2 k \sigma_{2}^{2} q_{1}+2 k \sigma_{2}^{2}\left(D_{1}+D_{2}\right)-\mu_{1}+\mu_{2}+\lambda_{2}=0, \\
\lambda_{1} q_{1}=0, \lambda_{2} Q_{1}=0, \\
\lambda_{1}, \lambda_{2} \geq 0 .
\end{gathered}
$$

The solutions of the K-T conditions are the optimal purchasing quantities, and they can be discussed in four cases.

(i) $\lambda_{1}=0, \lambda_{2}=0$

From Equations (8) and (9), we can get

$Q_{1}=\frac{c_{1}-\mu_{1}}{2 k \sigma_{1}^{2}}, q_{1}=\left(D_{1}+D_{2}\right)+\frac{\mu_{2}-c_{1}}{2 k \sigma_{2}^{2}}-\frac{c_{1}-\mu_{1}}{2 k \sigma_{1}^{2}}$.

(ii) $\lambda_{1}=0, \lambda_{2}>0$

From the K-T conditions, we can get

$Q_{1}=0, q_{1}=\left(D_{1}+D_{2}\right)+\frac{\mu_{2}-c_{1}}{2 k \sigma_{2}^{2}}$.

(iii) $\lambda_{1}>0, \lambda_{2}=0$

From the K-T conditions, we can get

$q_{1}=0, Q_{1}=\left(D_{1}+D_{2}\right) \frac{\sigma_{2}^{2}}{\sigma_{1}^{2}+\sigma_{2}^{2}}+\frac{\mu_{2}-\mu_{1}}{2 k\left(\sigma_{1}^{2}+\sigma_{2}^{2}\right)}$.

(iv) $\lambda_{1}>0, \lambda_{2}>0$

From Equation (10), we can get $q_{1}^{*}=0$ and $Q_{1}^{*}=0$. At this time, Equations (8) and (9) don't hold. Therefore, there are no solutions in this case.

Based on case (i) and case (ii), $q_{1}+Q_{1}=\left(D_{1}+D_{2}\right)+\frac{\mu_{2}-c_{1}}{2 k \sigma_{2}^{2}} . V_{1}\left(x_{1}\right)$ is concave of $q_{1}$ and $Q_{1}$. As $\left(q_{1}^{*}+Q_{1}^{*}\right)$ is no larger than $\left(D_{1}+D_{2}\right), q_{1}^{*}+Q_{1}^{*}=\left(D_{1}+D_{2}\right)+\frac{\mu_{2}-c_{1}}{2 k \sigma_{2}^{2}}$ if $\mu_{2}<c_{1} ; q_{1}^{*}+Q_{1}^{*}=D_{1}+D_{2}$ if $\mu_{2} \geq c_{1}$. 
Based on case (iii), if $\left(D_{1}+D_{2}\right) \frac{\sigma_{2}^{2}}{\sigma_{1}^{2}+\sigma_{2}^{2}}+\frac{\mu_{2}-\mu_{1}}{2 k\left(\sigma_{1}^{2}+\sigma_{2}^{2}\right)}<D_{1}+D_{2}, q_{1}^{*}+Q_{1}^{*}=\left(D_{1}+D_{2}\right) \frac{\sigma_{2}^{2}}{\sigma_{1}^{2}+\sigma_{2}^{2}}+\frac{\mu_{2}-\mu_{1}}{2 k\left(\sigma_{1}^{2}+\sigma_{2}^{2}\right)}$; otherwise, $q_{1}^{*}+Q_{1}^{*}=D_{1}+D_{2}$. Therefore, proposition 3 is true.

Corollary 3. When the contract price of raw materials increases $\left(c_{1}<c_{2}\right)$, the total materials purchased in period 1 increase in $k$.

Proof:

From case (i) of Proposition 3, if $\mu_{2} \geq c_{1}, q_{1}^{*}+Q_{1}^{*}=D_{1}+D_{2}$. As $k$ increases, $\left(q_{1}^{*}+Q_{1}^{*}\right)$ remain the same. If $\mu_{2}<c_{1}, q_{1}^{*}+Q_{1}^{*}=\left(D_{1}+D_{2}\right)+\frac{\mu_{2}-c_{1}}{2 k \sigma_{2}^{2}} \cdot \mu_{2}-c_{1}<0$, so $\left(q_{1}^{*}+Q_{1}^{*}\right)$ increases in $k$ in this case. Similarly, the same is true in the other cases. Therefore, Corollary 3 is true.

The optimal purchasing strategy can be determined as follows:

First, the purchasing strategy in period 1 can be determined according to the trend in contract prices. If the contract price increases, one should adopt the strategy of proposition 3; if the contract price decreases, one should adopt the strategy of proposition 2 . Second, the inventory level at the beginning of period $2, x_{2}$, can be obtained, which is equal to the total purchasing quantity less the quantity consumed in period 1 . Then the purchasing strategy in period 2 can be obtained from proposition 1 . Finally, an overall solution for the two-period model is obtained by combining the strategies of both periods.

\section{Performance Comparison}

We have obtained the optimal purchasing strategy by combining a long-term contract with a spot market. In this section, we use a numerical method to compare the performance level of a pure spot sourcing strategy with that of a mixed strategy. In the numerical analysis, parameters are set as follows: $r=20, D_{1}=D_{2}=100, k=0.005$. When the contract price decreases, $c_{1}=10.0, c_{2}=8.0, \mu_{1}=9.5, \mu_{2}=7.5$ ( or $\mu_{1}=10.5, \mu_{2}=8.5$ ), $\sigma_{1}=3.0, \sigma_{2}=3.5$; when the contract price increases, $c_{1}=10.0, c_{2}=13.0, \mu_{1}=9.5, \mu_{2}=12.5\left(\right.$ or $\left.\mu_{1}=10.5, \mu_{2}=13.5\right), \sigma_{1}=3.5, \sigma_{2}=3.5$.

\subsection{Pure Spot Market}

In this pure spot sourcing model, only a spot market is used. Therefore, $q_{1}=0$ and $q_{2}=0$.

When the contract price decreases, the buyer's purchasing strategy is $Q_{1}^{*}=D_{1}, Q_{2}^{*}=D_{2}$. 
When the contract price increases, the spot purchasing quantity in period $1 Q_{1}^{*}$ can be obtained from Equation (7), and the spot purchasing quantity in period 2 is $Q_{2}^{*}=D_{1}+D_{2}-Q_{1}^{*}$.

The expected profit in period 1 is $E\left(\pi_{1}\right)=r D_{1}-\mu_{1} Q_{1}^{*}$, and its variance is $\operatorname{Var}\left(\pi_{1}\right)=\left(Q_{1}^{*}\right)^{2} \sigma_{1}^{2}$. The expected profit in period 2 is $E\left(\pi_{2}\right)=r D_{2}-\mu_{2} Q_{2}^{*}$, and its variance is $\operatorname{Var}\left(\pi_{2}\right)=\left(Q_{2}^{*}\right)^{2} \sigma_{2}^{2}$.

\subsection{Performance Comparison}

After obtaining the optimal purchasing strategies of a pure spot sourcing model and a mixed sourcing model, we can make a comparison. Figures 2-5 show how the expected profits and utilities vary with $k$ when different purchasing strategies are used.

When the contract price falls, it can be seen from Figure 2 that the expected profit is lower in a mixed sourcing model than in a spot sourcing model if $\mu_{1} \leq c_{1}$. However, the expected profit of using a combined strategy is higher if $\mu_{1}>c_{1}$. As $k$ increases, the expected profit of using a combined strategy decreases, but the expected profit of using a spot market remains the same. From Figure 3, we can see that the utility is higher in a mixed sourcing model than in a spot sourcing model. The utility of using a combined strategy changes little in $k$, and the utility of using a spot market decreases quickly in $k$.
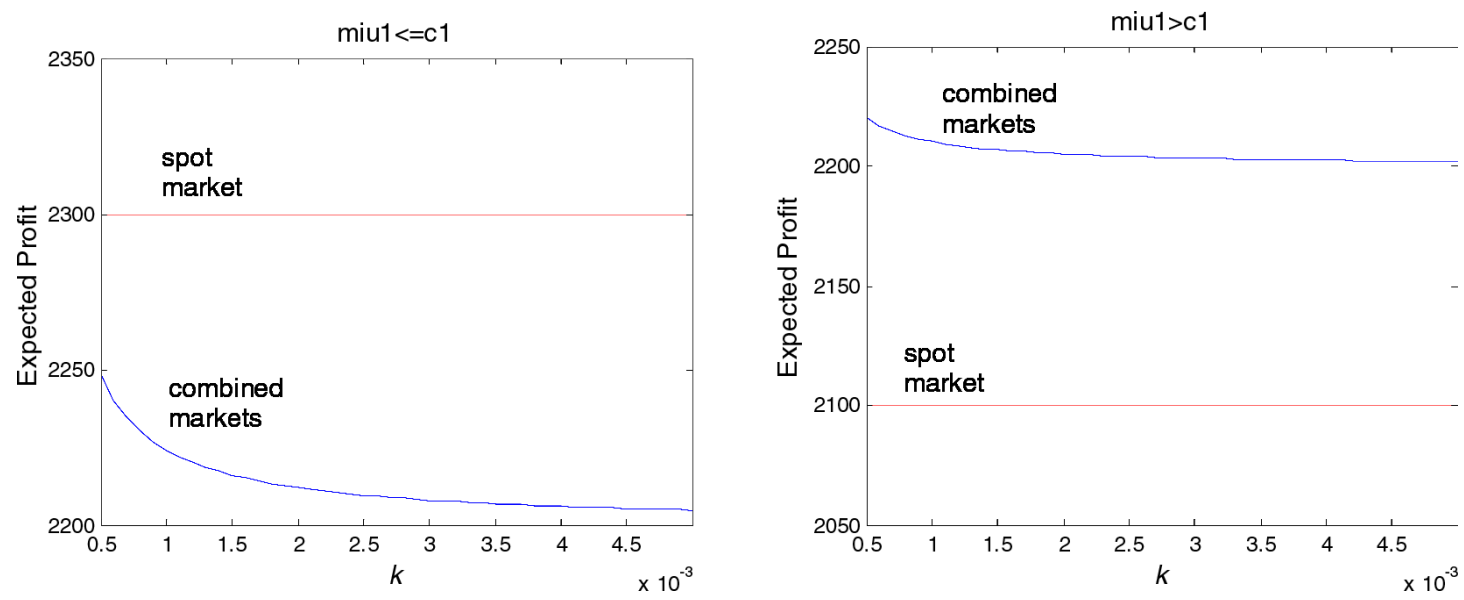

Figure 2. Profit comparison when the contract price falls 

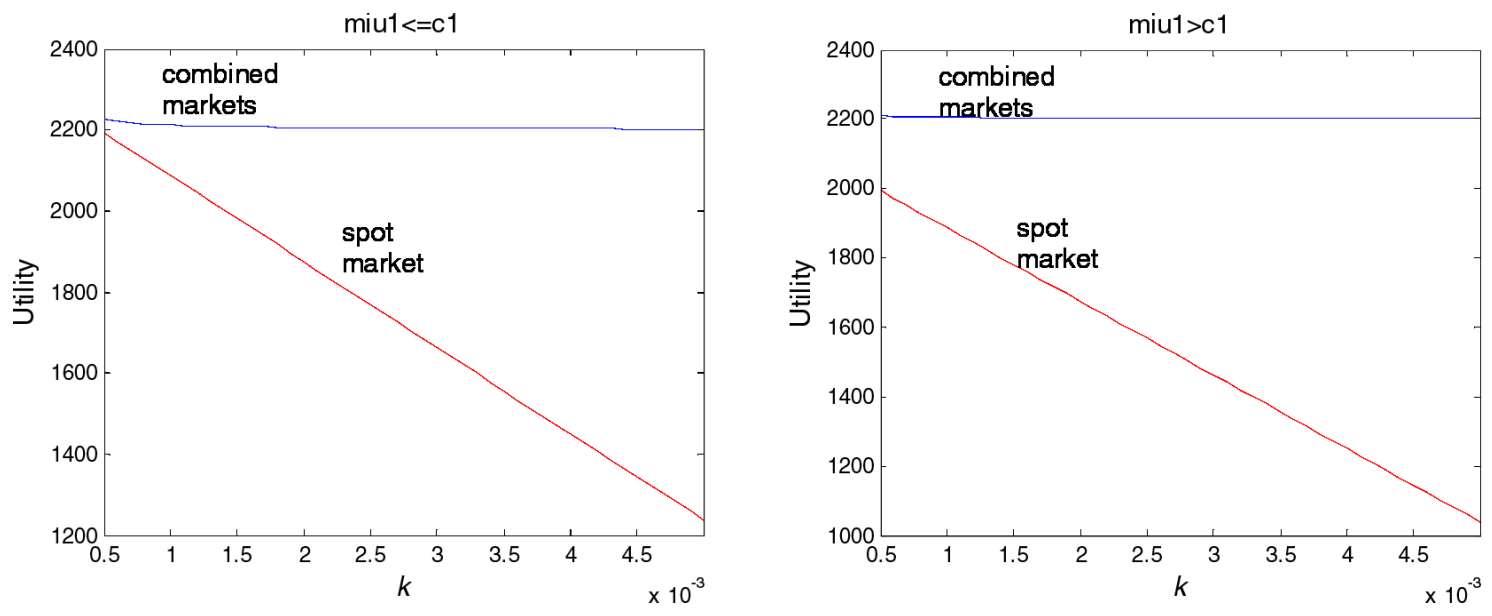

Figure 3. Utility comparison when the contract price falls

When the contract price increases, it can be seen from Figures 4-5 that the expected profit and the utility are higher in a mixed sourcing model than in a spot sourcing model. If the buyer becomes more risk-averse, both of the expected profits decrease. Just like the case when the contract price falls, the utility of using a combined strategy changes little in $k$, and the utility of using a spot market decreases quickly in $k$.
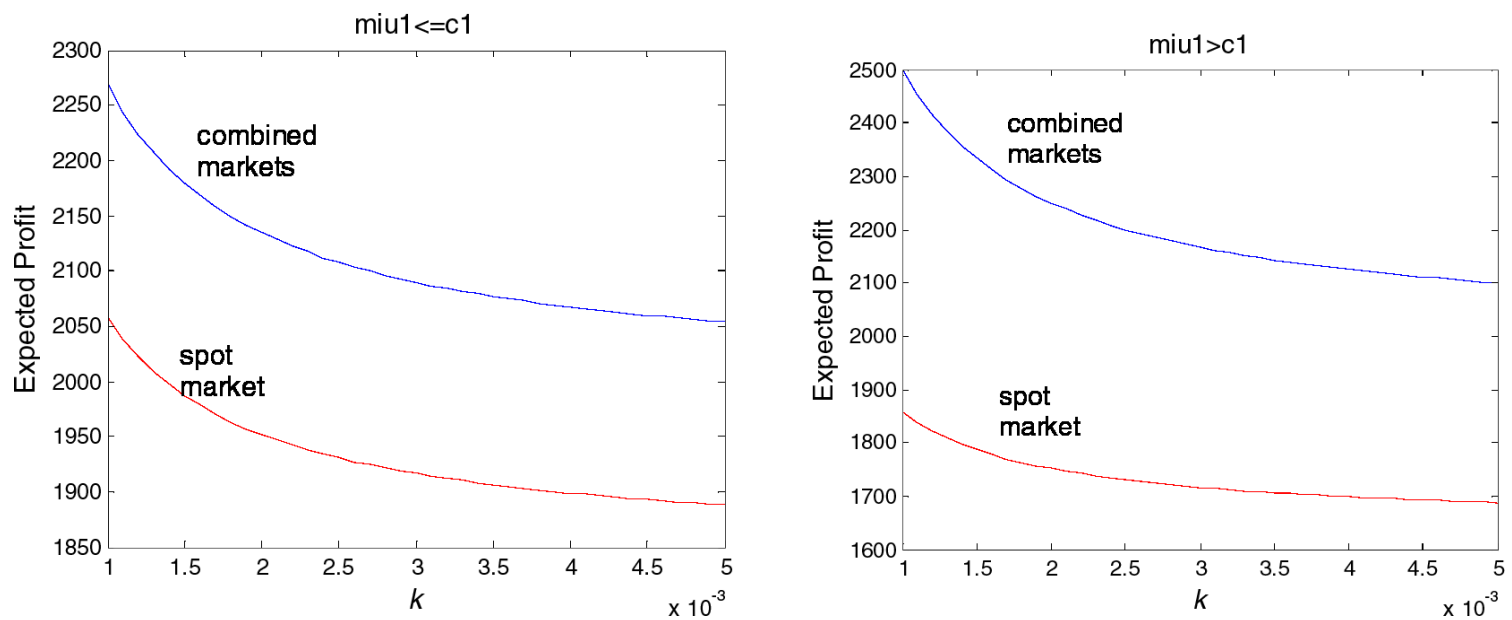

Figure 4. Profit comparison when the contract price increases 

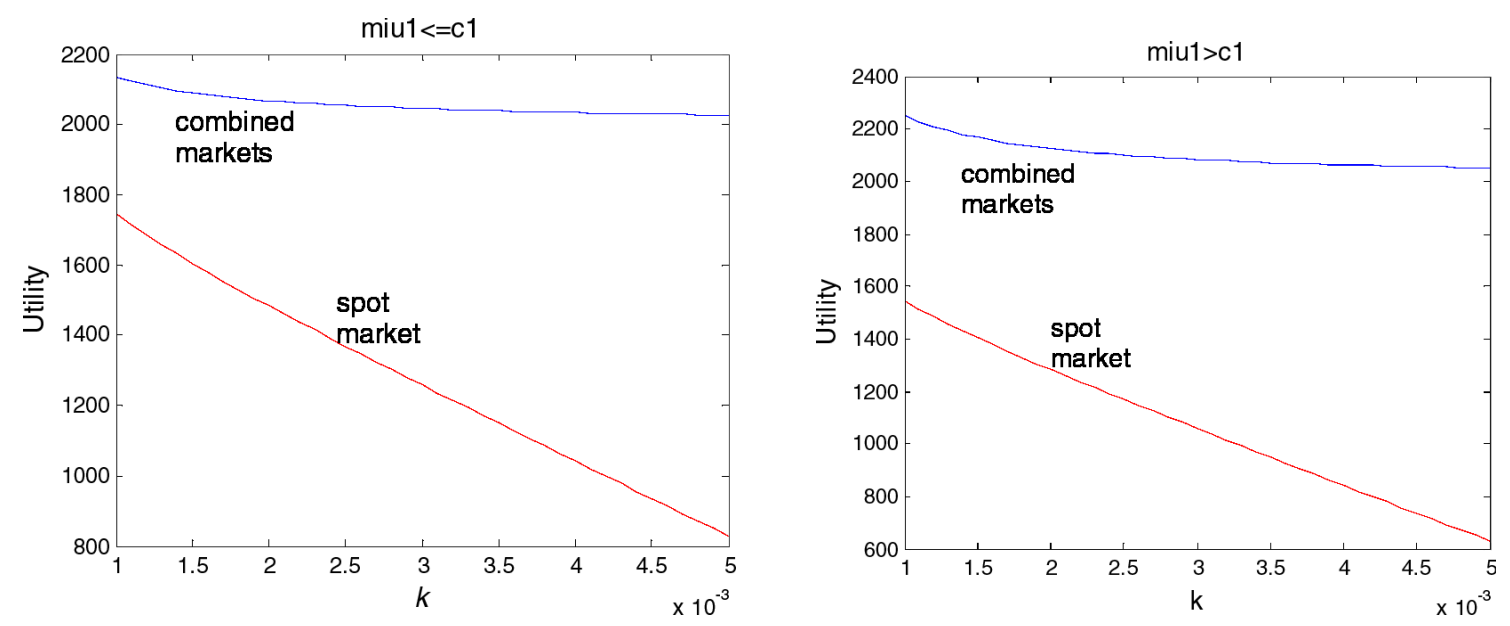

Figure 5. Utility comparison when the contract price increases

From the two cases above, we can obtain that the buyer's expected profit is not necessarily higher in a mixed sourcing model than in a spot sourcing model. However, the buyer's utility of using a combined strategy is always higher. The profit when buying via a spot market has a bigger variance, resulting in a lower utility. As $k$ increases, both of the utility levels will decrease. The utility of using a combined strategy decreases less, and the utility of using a spot market drops more. Therefore, a combined strategy is the optimal purchasing strategy for a riskaverse DM.

\section{Conclusion}

This paper studies a two-period purchasing model for a risk-averse manufacturer who procures raw materials under spot price uncertainty. The manufacturer can procure raw materials via a long-term contract and a spot market. Optimal purchasing strategies are obtained through dynamic programming.

Our results show that optimal purchasing strategies in period 1 are different, depending on the trend of the contract price. When the contract price falls, the total quantity purchased in period 1 decreases in $k$. When the contract price increases, the total quantity purchased in period 1 increases in $k$. Then the purchasing strategy in period 2 will be determined. The relationship between the optimal contract quantity $q_{2}^{*}$ and the degree of risk aversion $k$ depends on whether the expected spot price or the contract price is larger in period 2 . The contract quantity and spot quantity in each period are also given.

Finally, the performance levels are compared while the manufacturer adopts a combined strategy and a spot sourcing strategy. A numerical analysis shows that a combined strategy is 
optimal for a risk-averse buyer. The buyer's risk aversion factor $k$ has a smaller influence on the utility of a mixed strategy than on the utility of a spot sourcing strategy.

This study provides a solution that is easy to implement in practice for a buyer who is confronted with the price risk of raw materials. A long-term contract and a spot market can be combined to reduce procurement risk and help to increase operational flexibility.

\section{Acknowledgement}

This research was supported by the Key Research Center of Philosophy and Social Science of Zhejiang Province: Modern Port Service Industry and Creative Culture Research Center (No. 13JDLG01Z).

\section{References}

Araman, V., Kleinknecht, J., \& Akella, R. (2001). Seller and procurement risk management in e-business: Optimal long-term and spot market mix. Department of Management Science and Engineering, Stanford University, Stanford, CA.

Arnold, J., \& Minner, S. (2011). Financial and operational instruments for commodity procurement in quantity competition. International Journal of Production Economics, 131(1), 96-106. http://dx.doi.org/10.1016/j.ijpe.2010.02.007

Chung, C.S., \& Flynn, J. (2001). A newsboy problem with reactive production. Computers \& Operations Research, 28(8), 751-765. http://dx.doi.org/10.1016/S0305-0548(00)00006-X

Cohen, M., \& Agrawal, N. (1999). An analytical comparison of long and short term contract. IIE Trans, 31(8), 783-796. http://dx.doi.org/10.1080/07408179908969877

Donohue, K. (2000). Efficient supply contracts for fashion goods with forecast updating and two production modes. Management Science, 46(11), 1397-1422.

http://dx.doi.org/10.1287/mnsc.46.11.1397.12088

Fu, Q., Lee, C., \& Teo, C. (2010). Procurement management using option contracts: Random spot price and the portfolio effect. IIE Transactions, 42(11), 793-811.

http://dx.doi.org/10.1080/07408171003670983

Gan, X., Sethi, S.P., \& Yan, H. (2004). Channel coordination of supply chains with risk-averse agents. Production and Operations Management, 13(2), 135-149. http://dx.doi.org/10.1111/j.19375956.2004.tb00150.x

Ganeshan, R., Boone, T., \& Aggarwal, P. (2009). Optimal procurement portfolios when using B2Bs: A model and analysis. International Journal of Production Economics, 118, 146-151. http://dx.doi.org/10.1016/j.ijpe.2008.08.041 
Inderfurth, K., \& Kelle, P. (2011). Capacity reservation under spot market price uncertainty. International Journal of Production Economics, 133(1), 272-279.

http://dx.doi.org/10.1016/j.ijpe.2010.04.022

Kleindorfer, P.R., \& Wu, D.J. (2003). Integrating long-term and short-term contracting via business-to-business exchanges for capital-intensive industries. Management Science, 49(11), 1597-1615. http://dx.doi.org/10.1287/mnsc.49.11.1597.20583

Kleindorfer, P.R., \& Wu, D.J. (2005). Competitive options, supply contracting, and electronic markets. Management Science, 51(3), 452-466. http://dx.doi.org/10.1287/mnsc.1040.0341

Kouvelis, P., Li, R., \& Ding, Q. (2013). Inventory management and financial hedging of storable commodities. M\&SOM, 15(3), 507-521. http://dx.doi.org/10.1287/msom.2013.0433

Lee, H., \& Whang, S. (2002). The impact of the secondary market on the supply chain. Management Science, 48(6), 719-731. http://dx.doi.org/10.1287/mnsc.48.6.719.189

Nagali, V., Hwang, J., Sanghera, D., Gaskins, M., Pridgen, M., Thurston, T. et al. (2008). Procurement risk management (PRM) at Hewlett-Packard company. Interface, 38(1), 51-60. http://dx.doi.org/10.1287/inte.1070.0333

Peleg, B., Lee, H., \& Hausman, W. (2002). Short-term e-procurement strategies versus long-term contracts. Production and Operations Management, 11(4), 458-479.

http://dx.doi.org/10.1111/j.1937-5956.2002.tb00472.x

Seifert, R.W., Thonemann, U.W., \& Hausman, W.H. (2004). Optimal procurement strategies for online spot markets. European Journal of Operational Research, 152(3), 781-799. http://dx.doi.org/10.1016/S0377-2217(02)00754-3

Serel, D.A. (2007). Capacity reservation under supply uncertainty. Computers and Operations Research, 34, 1192-1220. http://dx.doi.org/10.1016/j.cor.2005.06.018

Serel, D., Dada, M., \& Moskowitz, H. (2001). Sourcing decisions and capacity reservation contracts. European Journal of Operational Research, 131(3), 635-648. http://dx.doi.org/10.1016/S0377-2217(00)00106-5

Warburton, R.D.H., \& Stratton, R. (2005). The optimal quantity of quick response manufacturing for an onshore and offshore sourcing model. International Journal of Logistics: Research and Applications, 8(2), 125-141. http://dx.doi.org/10.1080/13675560500166798

Wu, D.J., Kleindorfer, P.R., \& Zhang, J.E. (2002). Optimal bidding and contracting strategies for capital-intensive goods. European Journal of Operational Research, 137, 657-676. http://dx.doi.org/10.1016/S0377-2217(01)00093-5

Journal of Industrial Engineering and Management, 2015 (www.jiem.org)

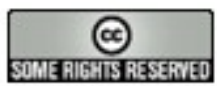

Article's contents are provided on a Attribution-Non Commercial 3.0 Creative commons license. Readers are allowed to copy, distribute and communicate article's contents, provided the author's and Journal of Industrial Engineering and Management's names are included. It must not be used for commercial purposes. To see the complete license contents, please visit http://creativecommons.org/licenses/by-nc/3.0/. 